\title{
Near-Peer - A Learning Modality
}

Hetal Satish Purohit ${ }^{1}$, Sweta Kale Pisulkar², Surekha Dubey Godbole ${ }^{3}$, Seema Sathe Kambala ${ }^{4}$, Gajanan Laxman Pisulkar ${ }^{5}$

1, 2, 3, 4, 5 Department of Prosthodontics and Crown \& Bridge, Sharad Pawar Dental College,

DMIMS (DU), Sawangi (M), Wardha, Maharashtra, India.

\section{ABSTRACT}

This review explains about the concepts and significance of PAL (Peer Assisted Learning) and the necessity of incorporation of these methods as a teaching-learning modality. Dental profession recognizes the importance of students being both learners and teachers. This concept aims at providing enhanced learning and teaching skills and a better understanding amongst them. Both the student and the teacher are benefitted.

PAL basically is selection of an individual amongst the students with a slightly higher intellect who can teach his peer groups by understanding the concept and the subject from their teachers. Thus, the concept has got revolutionary changes in better understanding of the concept. PAL also provides an opportunity to the peer tutors to perform and teach their peer group. Inclusion of peer-assisted learning (PAL) in the curriculum provided students with multiple opportunities to function as both a peertutor and a peer-learner. The rise in international interest in PAL appears to be a consequence of the global increase in medical student intake, limited teaching resources, and an emergent reference to teaching and assessment capabilities as

This learning modality resulted in great outcome as compared to the conventional teaching learning method in the literature published.

Peer-assisted learning was found to be an effective teaching-learning method among the students. Students also suggested that it should be used in complement to the traditional teaching modality. These concepts can be further added into the curriculum of various other fields of education. Studies have also shown increase in the intellect of the peer group and tutor group comparatively and performed better.

\section{KEY WORDS}

Peer Tutor, Peer Assisted Learning, Supplemental Instructions
Corresponding Author: Dr. Sweta Kale Pisulkar. 202, Department of Prosthodontics, Sharad Pawar Dental College and Hospital, DMIMS (DU), Sawangi (M),

Wardha - 442001, Maharashtra, India. E-mail:drsweta15@gmail.com

DOI: $10.14260 / \mathrm{jemds} / 2020 / 761$

How to Cite This Article:

Purohit HS, Pisulkar SK, Godbole SD, et al. Near-peer - a learning modality. J Evolution Med Dent Sci 2020;9(46):3479-3482, DOI: 10.14260/jemds/2020/761

Submission 10-08-2020,

Peer Review 04-10-2020,

Acceptance 10-10-2020,

Published 16-11-2020.

Copyright (C) 2020 Hetal Satish Purohit et al. This is an open access article distributed under Creative Commons Attribution License [Attribution 4.0 International (CC $B Y 4.0)]$ 


\section{BACKGROUND}

"Anyone who has ever taught knows that the best way to learn something is to teach it to someone else". This fundamental principle reinforces the concept of peer tutoring, wherein 'peers' are commonly regarded as being persons of slightly higher intelligent status. There are a lot of reasons why so many medical schools worldwide implemented Peer Assisted Learning (PAL) as one of their teaching and learning strategies since the last few decades. One of the reasons is because of insufficient faculty members to get involved in teaching and learning activity.

Topping KJ ${ }^{1}$ in 1996 , Santee J, Garavalia L.in $2006,^{2}$ Sobral DT in $2002^{3}$ discussed about recruitment of clinician staff members for attending the training sessions due to the conflicts with the service obligations become a challenging task for the medical staff. Therefore, one of the promising strategies to overcome these issues is by using PAL approaches. There is also lack of enthusiasm among clinicians in teaching in 'laboratory setting' and some of them tend to give didactic lecture instead of practical hands-on learning skills which are required. Due to all these reasons the use of PAL is an appealing adjunct. PAL is in its emerging trend as one of the effective teaching and learning strategies in medical school.

'Peers' are not professional teacher or subject matter experts. They might share certain characteristic but not necessarily come from the same course or year of study and shouldn't be significantly different in status or qualification.

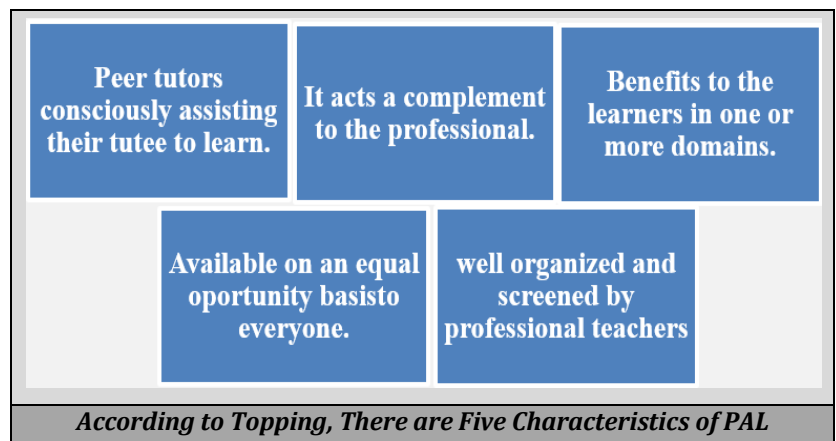

HISTORICAL BACKGROUND OF PAL

Peer education has been around for many years and many higher education providers in the United States of America, United Kingdom, Australia and others have used different models of Supplemental Instruction (SI), especially for firstyear students. This is based on the premise that Peer Assisted Learning (PAL) has significant positive effects on study achievement. A theory by Ibraheem MD, Aijaz N. in 20114 postulated learning is group behaviour. Thus PAL, which involves group interaction, should bring about better learning. Peer Assisted Study Sessions, is one of the models of PAL, mentioned by Dobbie M, Joyce S. in $2009^{5}$ and it is adopted widely in the context of higher education and across different disciplines as "a means of facilitating student learning". In a Literature review by Lila Mauigoa-Tekene in 2013 mentioned about PAL is derived from the model of Supplemental Instruction, which was found by Dr Deanne Martin at the
University of Missouri, Kansas City in 1973. Since the inception of the SI model, assortments of similar models have emerged and different countries around the world use them to enrich formal classroom instructions.

The origin of PAL, in the UK, was found in secondary education. Senior peers would work with junior partners in the classroom, exchanging learning habits and strategies. Not only does the junior partner develop through this interaction but also helps the seniors. Depending on the type of scheme being employed, the peer can be more or less actively engaged with their junior partner in order to successfully achieve aims. A peer assisted learning scheme (PALs) will generally aim to facilitate one or a combination of each of the following outcomes:

- The acquisition of skills (what I can do).

- Developing motivation (how much I want to be able to know and do).

- Developing confidence (my belief that I am able to know and do).

There are variations in the techniques and types of peer assisted learning modalities. Each type or method can deliver the above outcomes to varying degrees. So it is of utmost importance to consider the aims of a particular PAL prior to selection of the type that is to be employed. The most frequently found types of PAL are listed.

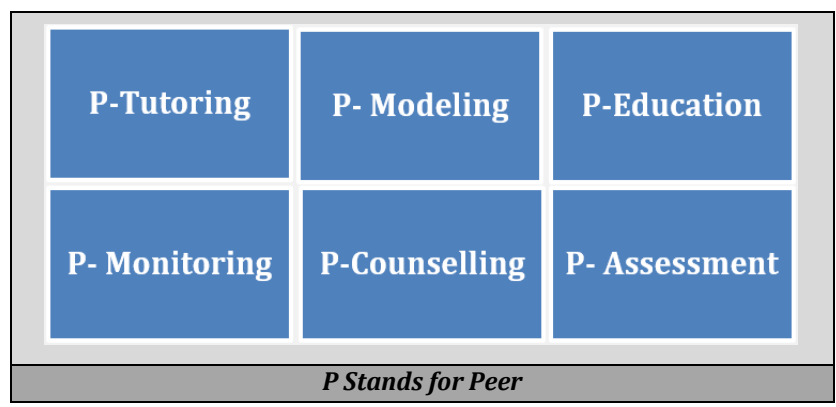

However, PAL at the University of Edinburgh draws on an amalgamated approach, utilising suitable aspects of each of the above-mentioned types. Ross MT, Cameron HS in $2007^{6}$ have also included peer review, peer appraisal, collaborative learning, etc. under the umbrella of PAL. The conveyance of each of these specific features is through simplification and not teaching. So, the senior student working with the junior partner (frequently a first year) takes the role of facilitator and not teacher, this is an important distinction. As a result, 'the acquisition of knowledge' is not what such schemes in Edinburgh focus on, rather the three other areas of skills, motivation and confidence. Some of the aspects that can be facilitated by PAL at Edinburgh include; so many different methods to employ under the banner of PAL, which itself can be considered a type of cooperative learning, it is unsurprising that the nomenclature is often corrupted and incorrectly was described by Makala $Q$ in 2017.7 It is also difficult to imagine singularly employing one method such as P-tutoring:

- Emphasis on syllabus content (peer tutoring).

- The modelling of enthusiasm, determination and support (peer modelling).

- Conversation regarding the resources in a comfortable group situation (peer education).

- Noticing and providing opinion on learning schemes (peer monitoring).

- Providing vision on overall learner's life (peer 
counselling).

- Conversing experiences around first submissions, essays $\&$ lab reports (peer assessment).

\section{NEED FOR PEER-ASSISTED LEARNING IN MEDICAL AND ALLIED HEALTH EDUCATION}

There is an extensive list of recognized qualitative gains that was devised from peer-teaching strategies in the setting of health professional education. These range from variably inclusive of improved cognitive, psychomotor and affective development. With additional gains of economic benefits with collegial behaviour amongst the learners. The literature also emphasizes on the measured educational benefits subjectively as well as objectively as a whole. The subjective benefits and student features are linked with preferences, satisfaction from learner, tutor-learner satisfaction, confidence, learner's leadership skills and learning opportunities.

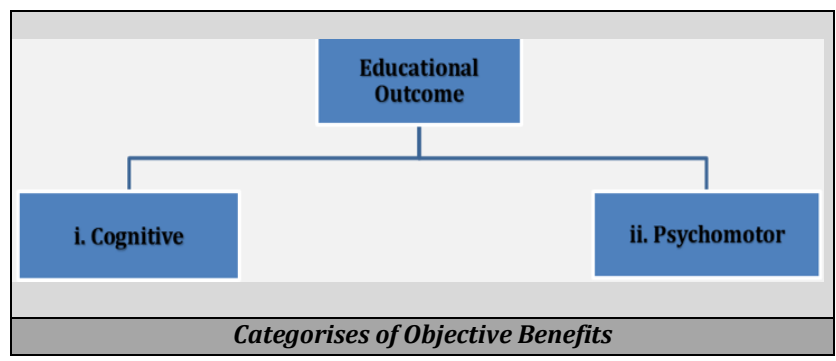

The passion for medical students as peer-tutors can also be found in literature. The significance is more widespread than documented. The documentation in the literature still lacks objective clarity about the effectiveness of the peer assisted learning on the basis of duration, outcomes, opportunities and skill development in clinics for medical schools. Despite of the rising theoretical based applied literature the medical schools globally focuses on peer teaching was discussed by Ross MT, Cameron HS in 2007.6

\section{PEER AS TUTOR AND LEARNER - A STRATEGY}

Concepts of the peer tutoring evaluates both the learning and teaching strategies simultaneously, as the peer also has the role of a learner initially. Varied means and modes of teachinglearning takes place in medical schools. Concept of reciprocal peer tutoring was put forth by Hendelman WJ in $1986^{8}$ and is often seen in the laboratory settings wherein, students play a dual role between the tutor and the learner as and when required.

\section{Effectiveness of PAL}

Studies have proven that PAL is one of the effective strategies in tutor-learner activity in medical school systems. The advantages to the tutors, tutees as well as for the institution are found in many literatures. Systematic review done by TzuChieh Yu et al in $2011^{9}$ also has proven the effectiveness of PAL in medical education. It was found that there are positive results of peer teaching-learning in several aspects, which are; increase in student's confidence in clinical practice and improves the educational outcome domains. In the literature it has been proven to have a positive impact on the educational outcome domains by Secomb J.A in $2008^{10}$ and Schaffer JL, Wile MZ, Griggs RC in 1990.11

\section{Student Tutor versus Professional Tutor}

Students who learnt using PAL gained knowledge and training which was similar to that obtained from an expert .Also found similar finding in the studies done by Field M, Burke JM, McAllister D, Lloyd DM. in 2007,12 Tolsgaard MG, in 2007,13 Haist SA in 1998.14 The students trained by their peers (student tutors) performed better in comparison with the students trained by professional tutors was proved by Tolsgaard MG, in 2007.13 The reliability of student tutors were comparatively more as described by Perkins GD, Hulme J, Bion JF in 2002.15 The main reason being the student tutors are more approachable for the learners than the professional tutors. Cornwall MG in $1980^{16}$ stated tutoring has also benefitted peer teaching in Higher Education.

In the study done by Makala Q in 2017,7 Hendelman WJ8 in 1986 and Tzu-Chieh Yu et al in $2011^{9}$ stated student tutors have proven to have positive impact in learners' participation in teaching and learning activities. Peers were also considered more approachable and put concepts in context better than professional tutors. They were also considered less 'intimidating' when asking questions.

Data evaluated by Schaffer JL, Wile MZ, Griggs RC in $1990^{11}$ has shown that there was a significant relationship between students' participation in peer tutorial program and performance on their examinations. By the use of peer teachers, students' performances on examination are not weakened, was concluded by Haist SA in 1998.14 Kathleen S. Hughes in $2011^{17}$ has found that in voluntary peer teaching session, there was a strong positive correlation between students' attendance to peer assisted learning session and their final examination grades. Dr Muhd Al-Aarifin Ismail stated in other words that students who voluntarily attend more PAL session with their peer tutor got higher grade compared to students who attend less.

\section{Benefits of Peer}

Whitman NA, Fife JD in $1988^{18}$ stated PAL is not only beneficial for tutees, the benefits also go to peer tutors as well. As we know it, the most efficient way to learn is to teach. Bales through his pyramid of learning average retention shows - $5 \%$ recall rate through learning from listening to lectures, whereas tutoring colleagues, leads to $80 \%$ retention. Ten Cate 0 , Durning S in $2007^{19}$ on comparing other learning methods, concluded that some tutors understand better when they teach themselves rather than listening or reading.

Sobral DT in $2002^{3}$ stated that, the role of being a peer tutor can be an interesting and productive scholastic opportunity to enhance students' academic development. Improved skills is relative to the tutoring experiences. Moreover, becoming student tutors may aid students in building upshots regarding choice of career in their future is proven by Sobral DT in 2002,3 Makala Q in 2017,7 Hendelman WJ in $1986^{8}$ and Tzu-Chieh Yu et al in 2011, ${ }^{9}$ Cornwall MG in 1980,16 Jolene M. Henning; Thomas G. Weidner; Melissa C. Marty in 2008,20 Dr Muhd Al-Aarifin Ismail. 


\section{THE PROS AND CONS OF PAL}

The concept of PAL has gained its popularity in clinical stream in medical schools as well as other fields of educational settings. PAL as a learning tool is used for training the undergrads in medical schools. The concept of "cross peer" is in which one senior works and supervises a small group comprising of young peer participants. The literature has proven facts that the concept of peer learning works well.

\begin{tabular}{|c|c|}
\hline Pros & Cons \\
\hline Greater grades in cognitive reasoning & $\begin{array}{l}\text { Rise in requirement for training and } \\
\text { resources, at initial stages. }\end{array}$ \\
\hline Improved interpersonal skills & Extensive curriculum coverage. \\
\hline Improved self-esteem & \multirow{7}{*}{$\begin{array}{l}\text { Raise apprehensions about } \\
\text { governance, relevance and efficacy. }\end{array}$} \\
\hline Greater motivation towards learning & \\
\hline Greater dynamic learner involvement & \\
\hline Enhanced team discipline & \\
\hline Advancements in teaching skills & \\
\hline Rare usage of institutional resources & \\
\hline Economical educational tool. & \\
\hline \multicolumn{2}{|c|}{ Table 2. Pros and Cons of PAL } \\
\hline
\end{tabular}

PAL is meant for its capability to inspire learners to participate and contribute to the learning activity. This gives learners ownership for their own learning, which subsequently leads to better conversational and cognitive participation. Through PAL, peer educators can develop generic skills such as communication, organization and presentation as well teaching skills and deeper understanding of the subject matter. The precise nature of benefit from peer teaching depends on the structure of the PAL's and the activity that engages the peer educator was explained by Anna Romito. There are other methods of teaching and learning for the students in medical schools that can be applied are explained by Gade, S.A., S.N. Chari, and A. Chalak.in 2017.21

\section{CONCLUSIONS}

Peer-assisted learning was found to be an effective teachinglearning method amongst the students. Peer-assisted was found to be an equally effective method as compared to the staff-led arm to impart knowledge, skills, and attitude required for effective learning. Students agreed to the utility of peerassisted learning as a teaching tool, but stressed that it should be used for complementing traditional teaching methods.

Financial or other competing interests: None.

Disclosure forms provided by the authors are available with the full text of this article at jemds.com.

\section{REFERENCES}

[1] Topping KJ. The effectiveness of peer tutoring in further and higher education: a typology and review of the literature. Higher Education 1996;32(3):321-45.

[2] Santee J, Garavalia L. Peer tutoring programs in health professions schools. Am J Pharm Educ 2006;70(3):70.
[3] Sobral DT. Cross-year peer tutoring experience in a medical school: conditions and outcomes for student tutors. Med Educ 2002;36(11):1064-70.

[4] Ibrahim MDB, Aaijaz N. Dynamics of peer assisted learning and teaching at an entrepreneurial university: an experience to share. International Journal of Humanities and Social Science 2011;1(12):93-9.

[5] Dobbie M, Joyce S. Does peer-assisted learning improve student marks in accounting? Asian Social Science 2009;5(10):3-9.

[6] Ross MT, Cameron HS. Peer assisted learning: a planning and implementation framework: AMEE Guide no. 30. Med Teach 2007;29(6):527-45.

[7] Makala Q. Peer-assisted learning programme: supporting students in high-risk subjects at the Mechanical Engineering Department at Walter Sisulu University. Journal of Student Affairs in Africa 2017;5(2):17-31.

[8] Hendelman WJ, Boss M. Reciprocal peer teaching by medical students in the gross anatomy laboratory. J Med Educ 1986;61(8):674-80.

[9] Yu TC, Wilson NC, Singh PP, et al. Medical students-asteachers: a systematic review of peer-assisted teaching during medical school. Adv Med Educ Pract 2011;2:15772.

[10] Secomb J. A systematic review of peer teaching and learning in clinical education. J Clin Nurs 2008;17(6):70316.

[11] Schaffer JL, Wile MZ, Griggs RC. Students teaching students: a medical school peer tutorial programme. Med Educ 1990;24(4):336-43.

[12] Field M, Burke JM, McAllister D, et al. Peer-assisted learning: a novel approach to clinical skills learning for medical students. Med Educ 2007;41(4):411-8.

[13] Tolsgaard MG, Gustafsson A, Rasmussen MB, et al. Student teachers can be as good as associate professors in teaching clinical skills. Med Teach 2007;29(6):553-7.

[14] Haist SA, Wilson JF, Brigham NL, et al. Comparing fourthyear medical students with faculty in the teaching of physical examination skills to first-year students. Acad Med 1998;73(2):198-200.

[15] Perkins GD, Hulme J, Bion JF. Peer-led resuscitation training for healthcare students: a randomized controlled study. Intensive Care Med 2002;28(6):698-700.

[16] Cornwall MG. Students as teachers: peer teaching in higher education. Amsterdam: Centrum 1980:32-9.

[17] Hughes KS. Peer-assisted learning strategies in human anatomy \& physiology. The American Biology Teacher 2011;73(3):144-7.

[18] Whitman NA, Fife JD. Peer teaching: to teach is to learn twice. ASHE-ERIC Higher Education Report No. 4, 1988. ASHE-ERIC Higher Education Reports. Washington, DC: The George Washington University 1988.

[19] Cate OT, Durning S. Peer teaching in medical education: twelve reasons to move from theory to practice. Med Teach 2007;29(6):591-9.

[20] Henning JM, Weidner TG, Marty MC. Peer Assisted learning in clinical education: literature review. Athletic Training Education Journal 2008;3(3):84-90.

[21] Gade SA, Chari SN, Chalak A. Use of mini-CEX as a teaching learning method in physiology for undergraduate medical students. National Journal of Physiology Pharmacy and Pharmacology 2017;7(5):482-5. 